\title{
Dissociating polysensitization and multimorbidity in children and adults from a Polish general population cohort
}

\author{
Filip Raciborski ${ }^{1}$, Jean Bousqet 2,3,4,6, Andrzej Namysłowski 1,7, Edyta Krzych-Fałta1,7, Aneta Tomaszewska', \\ Barbara Piekarska ${ }^{1}$, Piotr Samel-Kowalik' , Artur Z. Białoszewski ${ }^{1 *}$, Artur Walkiewicz' , Agnieszka Lipiec ${ }^{1,7}$, \\ Oksana Wojas ${ }^{1,7}$, Krzysztof Samoliński ${ }^{8}$, Anna Szylling ${ }^{7}$, Wojciech Zieliński ${ }^{1,9}$, Adam Sybilski ${ }^{1}$, \\ Aleksandra Grąbczewska ${ }^{1}$ and Bolesław Samoliński ${ }^{1,7}$
}

\begin{abstract}
Background: Links between multimorbidity of allergic diseases and allergen sensitization are still under debate, especially in adults. This study aimed to establish a relationship between polysensitization and allergic multimorbidity in children and adults and the allergens involved in multimorbidity.

Material and method: A cross-sectional multicentre study enrolled children aged 6-7 and 13-14 years and adults aged 20-44 years from a Polish national cohort. The diagnosis of allergic diseases was made by a physician. Skin prick tests to 13 allergens and serum IgE levels to 4 allergens were tested.

Results: Among the 3856 participants, single disease (asthma, allergic rhinitis or atopic dermatitis) was diagnosed in $27.7 \%$ subjects and allergic multimorbidity in $9.3 \%$. Allergic multimorbidity occurred more commonly in children than in adults $(\mathrm{p}<0.01)$. Asthma or atopic dermatitis alone were not associated with polysensitization. Rhinitis and multimorbidity were associated with polysensitization. Allergic multimorbidity occurred in $2.2 \%$ of participants with negative skin prick tests, $9.8 \%$ of those with one positive prick test (SPT $\geq 3 \mathrm{~mm}$ ) and $20.6 \%$ of polysensitized ones $(p<0.001)$. There was an increasing risk of multimorbidity depending on the number of positive prick tests for both SPT $\geq 3 \mathrm{~mm}$ (OR 9.6-16.5) and SPT $\geq 6 \mathrm{~mm}$ (OR 5.9-13.7). A statistically significant relationship was found between allergic multimorbidity and sensitization to cat and mite allergens.

Conclusions: Multimorbidity is associated with polysensitization especially in children compared with adults in Polish population cohort. New insights into single disease patterns were found: bronchial asthma is the strongest risk factor for the development of multimorbidity in comparison with allergic rhinitis and atopic dermatitis.
\end{abstract}

Keywords: Muitimorbidity, Polysensitization, IgE, Skin tests, Allergy, Asthma, Rhinitis, Urticaria, Atopic dermatitis

\section{Introduction}

Asthma (A), rhinitis (Rh) and atopic dermatitis (AD) are common chronic diseases. One of the most challenging characteristics is their complexity, with multiple genetic $[1-5]$ and environmental factors interlinked through IgEand non-IgE-associated mechanisms [6]. These diseases

\footnotetext{
*Correspondence: artur.bialoszewski@wum.edu.pl

${ }^{1}$ Department of Prevention of Environmental Hazards and Allergology,

Medical University of Warsaw, Warsaw, Poland

Full list of author information is available at the end of the article
}

generally begin very early in life and may persist across the life cycle [7]. They co-occur in the same subjects (multimorbidity) more often than expected by chance [5]. Multimorbidity is associated with $\operatorname{IgE}$ and non-IgE mechanisms. Moreover, the co-occurrence of these conditions appears to differ for various types of allergy [8].

There are several gaps in our knowledge. (i) Allergic multimorbidity has been studied in children and, more rarely, in adults [9]. However, no epidemiologic study has considered multimorbidity from childhood to adulthood. (ii) The type of allergic sensitization linked with 
multimorbidity is not yet fully understood. Asthma usually occurs less commonly in seasonal or intermittent allergic rhinitis (AR) in comparison to persistent allergy $[1,2,10-12]$. The relationship between atopic dermatitis and AR or A needs closer investigation in adults [12]. The role of urticaria, food or insect allergy is unknown in allergic multimorbidity, [11-15].

The phenotypic characterization of allergic diseases and the interactions between AR and A with sensitization suggests the importance of better characterization of subjects with allergic diseases and sensitisation to specific allergens for both clinical practice and mechanistic studies [16]. These studies are likely to impact the political agenda outlined by the Conclusion of the European Council on respiratory diseases among children [17-19].

\section{Objectives}

The aim of this study was to establish (i) a relationship between polysensitization and allergic multimorbidity in children and adults, (ii) the impact of other allergic and related diseases on multimorbidity and (iii) the allergens associated with single disease or multimorbidity.

\section{Methods}

The paper has been written according to the Strengthening the Reporting of Observational Studies in Epidemiology (STROBE) checklist (www.strobe-statement.org) [20].

\section{Study design}

The project Epidemiology of Allergic Diseases in Poland (ECAP) is an allergic epidemiological study conducted in Poland. It consists of two phases: an initial fieldwork phase (research grant from Ministry of Health and Ministry of Science and Higher Education (Poland) 03788/C.P05-6/2005) and a second laboratory-based study (research grant from the National Science Centre (Poland), 2011/01/B/NZ7/05289).

\section{Setting}

The ECAP is a cross-sectional multicentre study. The project includes three age categories: (i) children aged 6-7 and (ii) $13-14$ years and (iii) adults aged $20-44$ years living in the eight largest Polish urban centres (Warsaw, Lublin, Białystok, Gdańsk, Poznań, Wrocław, Katowice, Krakow) and one rural area (Zamość and Krasnystaws districts) (Additional File 1: Fig. 1).

The study comprised two main parts: (i) a questionnaire-based study (Computer-Assisted Personal Interview-CAPI); (ii) a complementary clinical assessment (spirometry with bronchodilator challenge, skin-prick tests (SPT), peak nasal inspiratory flow, and blood sampling for genetic and immune tests) [21]. Every third respondent participating in the questionnaire was recruited in a randomised procedure to participate in the complementary clinical assessment.

\section{Participants}

The stratified cluster sampling method was used to draw the research sample in each of the 9 centres. The sample was drawn from a personal identity number (PESEL) database (maintained by the Minister of Interior and Administration) which covers the entire population of Polish residents. Detailed information about the sampling and research methods is available on the ECAP website (http://ecap.pl/pdf/ECAP_metoda.pdf) [22].

\section{Data sources-measurement \\ Clinical examination}

During phase 2 of the study, each respondent was examined by a specialist in allergology who had participated in a training to harmonize clinical diagnoses. In adults, the diagnosis of $\mathrm{A}$ and $\mathrm{Rh}$ followed the pan-European study European Community Respiratory Health Survey II (ECRHS II) [23]. In children, the protocol and methodology of the International Study of Asthma and Allergy in Childhood (ISAAC) were used [24] without any modification. For AD, the criteria of Hanifin and Rajki were used [25].

\section{Skin-prick test}

Participants of phase 2 had a SPT [23] with the following 13 allergens: birch, grass pollen, mugwort, Dermatophagoides pteronyssinus (Der p), Dermatophagoides Farinae (Der f), dog, cat, hazel, alder, rye grass, plantain, Cladosporium, Alternaria negative control, histamine (Allergopharma, Reinbek, Germany). Single drops of allergen extracts (Allregopharma-Nexter) were administered at 2-5 cm-intervals using standard Morrow-Brown needles (0.9 $\mathrm{mm}$ long blade). The puncture was performed at a depth of approximately $0.4 \mathrm{~mm}$ and $0.01-0.5 \mu \mathrm{l}$ of allergen extracts were administered into a skin (expressed in biological unit $\mathrm{BU} / \mathrm{ml}$ ). The interpretation of skin prick test results (based on the guidelines of the European Academy of Allergy and Clinical Immunology [26]) was made after approximately $15-20 \mathrm{~min}$ in relation to positive (the histamine dihydrochloride at a concentration of $1.0 \mathrm{mg} / \mathrm{ml}$ ) and negative control (the saline). If the diameter of oedema was $>3 \mathrm{~mm}$, it indicated that a specific IgE for a given allergen was present in the skin. 
Each patient was skin tested on the volar surface of the forearm using 1-mm prick lancets. The skin reaction was recorded after $15 \mathrm{~min}$ by evaluating the skin response in comparison with the wheal produced by the positive and negative controls. A wheal diameter of at least $3 \mathrm{~mm}$ is considered a positive reaction according to the EAACI (European Academy of Allergy and Clinical Immunology) recommendation [26].

Due to cross reactions between allergens, the allergens were combined into 8 groups: (i) dog, (ii) cat, (iii) $\mathrm{Cla}$ dosporium herbarum, (iv) Alternaria tenuis, (v) Hazel, Alder and Birch, (vi), Der p and Der f (vii) Grass pollen and Rye grass, (viii) Mugwort and Plantain, although these weed pollens are not cross-reactive.

Positive SPT readings were recorded as weakly positive (SPT $\geq 3 \mathrm{~mm}$ ) or strongly positive (SPT $\geq 6 \mathrm{~mm}$ ).

\section{Specific lgE}

Serum specific IgE (sIgE) to $\mathrm{d} 1-D$ pteronyssinus, g6-Phleum pratense, m6-Alternaria alternata, and e1-cat was assayed by the CAP method (Thermofisher, Uppsala, Sweden). The following two thresholds were set for slgE values: $\geq 0.35 \mathrm{IU} / \mathrm{ml}$ (class $\geq 1$ ) and $\geq 0.7 \mathrm{IU} / \mathrm{ml}$ (class $\geq 2$ ).

\section{Variables}

The following definitions were adopted: allergic multimorbidity is the co-occurrence of at least two of the following three conditions: $\mathrm{A}, \mathrm{AR}$ and $\mathrm{AD}$. Other allergic diseases (e.g. food and venom allergy, and urticaria) were analysed but they were not included in the multimorbidity definition. Polysensitization is sensitization to at least two allergens or groups of allergens (sensitization to two allergens within the same group is not considered as polysensitization).

\section{Biases}

One of the problems of studies with two phases is the proportion of participants willing to have a complementary study. In the group of children (6-7 years) and adolescents (13-14 years), the attendance rate was higher than in the group of adults. Subjects with symptoms of allergic diseases were more willing to take part in the clinical assessment.

\section{Statistical methods}

The following statistical methods were used: descriptive analysis (e.g. frequencies, mean, median), bivariate analysis (crosstabs), multivariate analysis (logistic regression). The results were presented as odds ratio (including forest plot), confidence interval and p-value (Pearson's Chi squared). Multivariable regression model was used to reduce the potential impact of confounding factors.
Statistical analysis was restricted to subjects with complete data on the variables involved in the analysis. No data imputation method was involved.

All analyses were performed using IBM SPSS version 23 and 24. A significance level of 0.05 was assumed.

\section{Results}

\section{Participants}

The study group comprised 3856 subjects with complete clinical examination (including SPT and sIgE tests results) and questionnaire data (Fig. 1).

Characteristics of the study group are presented in Table 1 and Additional file 1: Table 1.

\section{Descriptive data}

Asthma was diagnosed in $10.8 \%$ of the participants, AR in $29.3 \%$ and $A D$ in $7.2 \%$ (Table 2). Asthma without AR or $\mathrm{AD}$ was found in $3.6 \%$ of the subjects. AR without A or $\mathrm{AD}$ was diagnosed in $20.5 \%$ of the subjects, and $\mathrm{AD}$ without A or AR in 3.7\% (Additional file 1: Table 2). A single disease (A, AR or AD) was observed in $27.7 \%$ of the subjects and allergic multimorbidity in $9.3 \%$ (8.4\% had dual morbidity, $0.9 \%$ had triple morbidity.

Allergic multimorbidity occurred in $10.7 \%$ of the 6-7-year-old children, in $10.9 \%$ of the 13-14-year-old children and in $7.6 \%$ of the adults $(\mathrm{p}<0.01)$. The prevalence of allergic multimorbidity was higher among men $(10.5 \%)$ than women $(8.3 \%)(\mathrm{p}<0.05)$ (Additional file 1: Fig. 2).

Positive SPTs $(\geq 3 \mathrm{~mm})$ to at least 1 group of allergens were seen in $44 \%$ of the study group. A strongly positive reaction $(\mathrm{SPT} \geq 6 \mathrm{~mm}$ ) to at least 1 group of allergens was present in $23.2 \%$. Among subjects without any positive SPT, allergic multimorbidity occurred in $2.3 \%$, compared

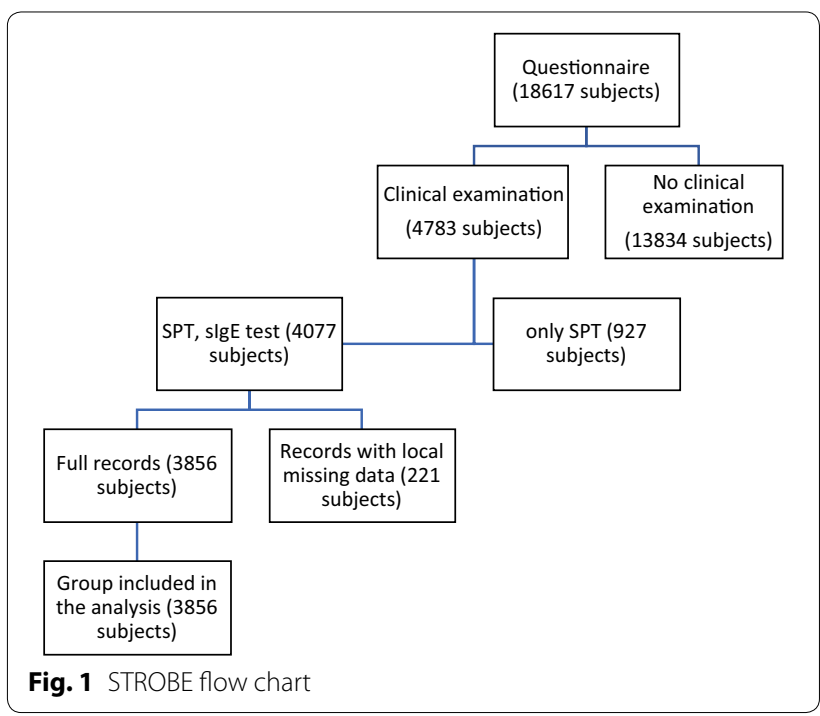


Table 1 Characteristics of the study group (\% in columns)

\begin{tabular}{|c|c|c|}
\hline & \multicolumn{2}{|l|}{ Total } \\
\hline & $\mathrm{N}$ & $\%$ \\
\hline Total & 3856 & 100 \\
\hline \multicolumn{3}{|l|}{ Age } \\
\hline $6-7$ years & 967 & 25.1 \\
\hline $13-14$ years & 1084 & 28.1 \\
\hline 20-24 years & 457 & 11.9 \\
\hline $25-29$ years & 353 & 9.2 \\
\hline $30-34$ years & 350 & 9.1 \\
\hline $35-39$ years & 320 & 8.3 \\
\hline 40-44 years & 325 & 8.4 \\
\hline \multicolumn{3}{|l|}{ Gender } \\
\hline Female & 2102 & 54.5 \\
\hline Male & 1754 & 45.5 \\
\hline \multicolumn{3}{|l|}{ Allergic diseases } \\
\hline Asthma & 415 & 10.8 \\
\hline Asthma alone (without AR, AD) & 138 & 3.6 \\
\hline Allergic rhinitis & 1130 & 29.3 \\
\hline Allergic rhinitis alone (without $A, A D$ ) & 790 & 20.5 \\
\hline Atopic dermatitis & 278 & 7.2 \\
\hline Atopic dermatitis alone (without A, AR) & 142 & 3.7 \\
\hline Food allergy & 344 & 8.9 \\
\hline Drug allergy & 165 & 4.3 \\
\hline Insect venom allergy & 94 & 2.4 \\
\hline Urticaria & 247 & 6.4 \\
\hline \multicolumn{3}{|l|}{ Positive SPT ( $\geq 3 \mathrm{~mm}$ ) } \\
\hline Control & 31 & 0.8 \\
\hline Histamine & 3617 & 93.8 \\
\hline Dog & 346 & 9.0 \\
\hline Cat & 512 & 13.3 \\
\hline Cladosporium & 212 & 5.5 \\
\hline Alternaria & 331 & 8.6 \\
\hline Hazel \& Alder \& Birch & 753 & 19.5 \\
\hline D. pteronyssinus \& D. farinae & 1039 & 26.9 \\
\hline Grass pollen \& Rye grass & 904 & 23.4 \\
\hline Mugwort, Plantain & 738 & 19.1 \\
\hline \multicolumn{3}{|l|}{ Positive slgE ( $\geq 1$ class) } \\
\hline $\mathrm{d} 1$-D. pteronyssinus & 563 & 14.7 \\
\hline g6-Phleum pratense & 509 & 13.3 \\
\hline m6-Alternaria alternata & 149 & 3.9 \\
\hline e1-cat & 235 & 6.1 \\
\hline \multicolumn{3}{|l|}{$\mathrm{SPTS}^{\mathrm{a}}$} \\
\hline All 8 SPTs negative & 2158 & 56 \\
\hline Only 1 of 8 SPTs $\geq 3 \mathrm{~mm}$ & 583 & 15.1 \\
\hline Polysensitisation ( $\geq 3 \mathrm{~mm}$ ) & 1115 & 28.9 \\
\hline All 8 SPTs $<6 \mathrm{~mm}$ & 2960 & 76.8 \\
\hline Only 1 of 8 SPTs $\geq 6$ mm & 506 & 13.1 \\
\hline Polysensitisation ( $\geq 6 \mathrm{~mm}$ ) & 390 & 10.1 \\
\hline \multicolumn{3}{|l|}{$\operatorname{slg} \mathrm{E}^{\mathrm{b}}$} \\
\hline All slgE in class 0 & 2885 & 74.8 \\
\hline
\end{tabular}

Table 1 (continued)

\begin{tabular}{lrr}
\hline & \multicolumn{2}{l}{ Total } \\
\cline { 2 - 3 } & $\mathbf{N}$ & $\%$ \\
\hline 1 of 4 slgE $\geq$ class 1 & 621 & 16.1 \\
Polysensitisation ( $\geq$ class 1) & 350 & 9.1 \\
All slgE class in 0 or 1 & 3032 & 78.6 \\
1 of 4 slgE $\geq$ class 2 & 571 & 14.8 \\
Polysensitisation ( $\geq$ class 2) & 253 & 6.6
\end{tabular}

$A R$ allergic rhinitis, $A D$ atopic dermatitis

a 8 groups of allergens

b 4 allergens

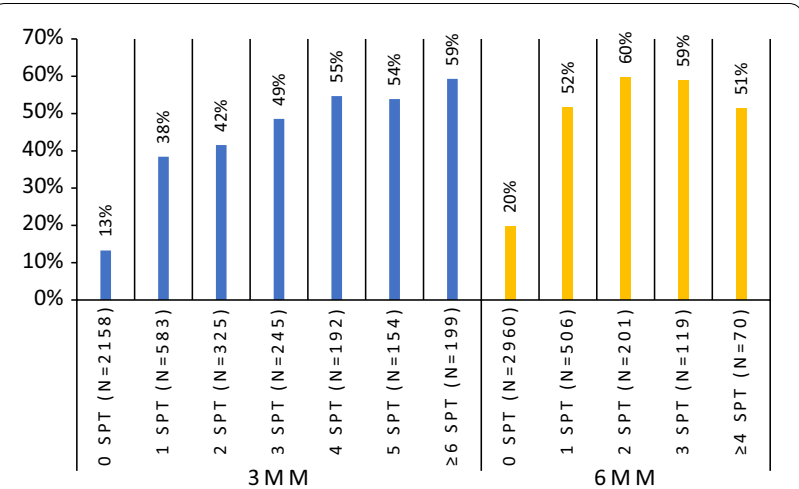

Fig. 2 Percentage of subjects with allergic multimorbidity by the number of positive SPTs (8 groups of allergens). $X$ axis — number of positive allergen skin prick tests. Y axis_\% of subjects with allergic multimorbidity

to $9.4 \%$ of those with one positive SPT ( $\geq 3 \mathrm{~mm}$ ) and $22.9 \%$ of polysensitized $(\mathrm{SPT} \geq 3 \mathrm{~mm})$ ones $(\mathrm{p}<0.001)$ (Additional file 1: Fig. 2).

Positive SPTs $(\geq 3 \mathrm{~mm})$ was most often observed for dust mites (Der $p$ and Der f: 26.9\%) and grass pollen (23.4\%). A positive (class $\geq 1$ ) slgE to Der $p$ was observed in $14.7 \%$ subjects, to cat in $6.1 \%$, to Phleum pratense in $13.3 \%$ and to Alternaria tenuis in $3.9 \%$.

\section{Main results: relationship between polysensitization and multimorbidity}

Of the conditions included in the definition of allergic multimorbidity, asthma had the greatest impact on the risk of multimorbidity $(\mathrm{OR}=82.2,95 \%$ CI 60.9-110.9) compared to $\mathrm{AR}(\mathrm{OR}=61.3,95 \% \mathrm{CI} 38.4-98.0)$ and $\mathrm{AD}$ $(\mathrm{OR}=14.4$ 95\% CI 10.9-18.9).

The occurrence of multimorbidity increased with the number of positive SPTs (Fig. 2). Allergic multimorbidity was strongly associated with polysensitization as assessed by skin tests (OR=7.5, 95\% CI 5.9-9.6). The highest association occurred between polysensitization and AR. A moderate relationship was found with $\mathrm{A}, \mathrm{AD}$, 


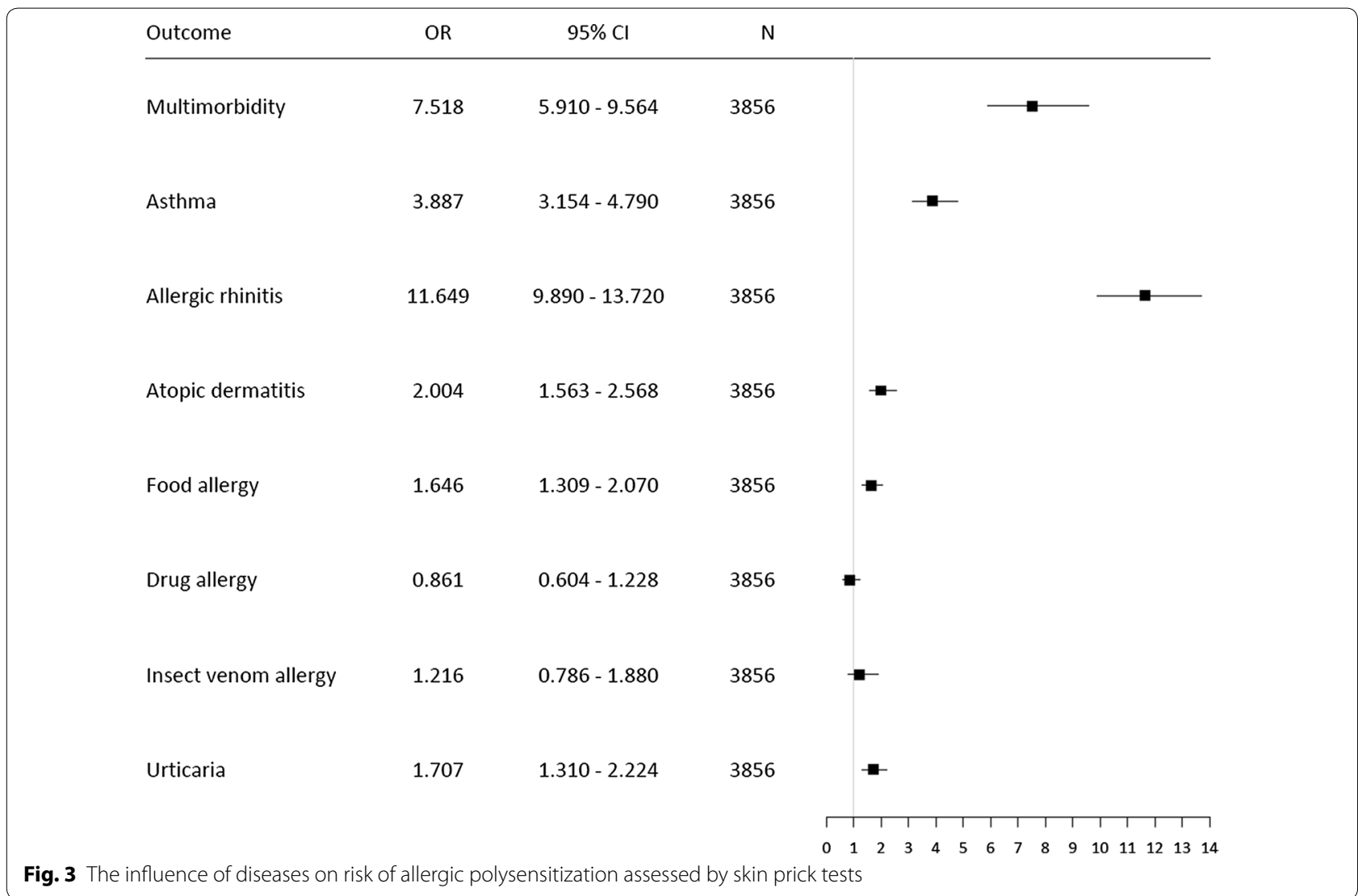

food allergy and urticaria (OR 2.0-3.9) (Fig. 3 and Additional file 1: Table 3).

Figure 4 and Additional file 1: Table 4 show that there was no statistically significant relationship (based on OR analysis) between A (as a single disease) and the number of positive SPTs (for both the $3 \mathrm{~mm}$ and $6 \mathrm{~mm}$ threshold). Results for AD were similar with two exceptions (for 1 SPT $(3 \mathrm{~mm})$ and 2 SPTs $(6 \mathrm{~mm})$ ). The risk of AR (as a single disease) increased with each additional positive SPT (OR 6.7-18.8 for SPT $\geq 3 \mathrm{~mm}$ and $6.0-8.2$ for $\geq 6 \mathrm{~mm}$ ). There was a relationship between allergic multimorbidity and the number of positive SPTs. For both thresholds ( $\geq 3 \mathrm{~mm}$ and $\geq 6 \mathrm{~mm}$ ) a higher number of positive SPTs was associated with a higher risk of multimorbidity
(OR 4.5-18.9 for the $3 \mathrm{~mm}$ threshold and 4.1-15.1 for $6 \mathrm{~mm}$ ). Differences between ORs for monosensitization $(\mathrm{SPT}=1)$ and polysensitization $(\mathrm{SPT} \geq 2)$ were statistically significant for the 3 and $6 \mathrm{~mm}$ thresholds $(\mathrm{p}<0.05)$.

A similar relationship between allergic multimorbidity and polysensitization was observed with sIgE levels. The prevalence of multimorbidity increased with the number of positive sIgE assays (Fig. 5 and Additional file 1: Fig. 2). This relationship was more pronounced in the analysis based on sIgE levels $\geq 0.70 \mathrm{IU} / \mathrm{ml}$ (class $\geq 2$ ).

The risk of multimorbidity also depended on the type of allergen, increasing from moulds (Alternaria tenuis OR 3.4, Cladosporium herbarum OR 3.7) to mites (OR 5.9) (Fig. 6). 


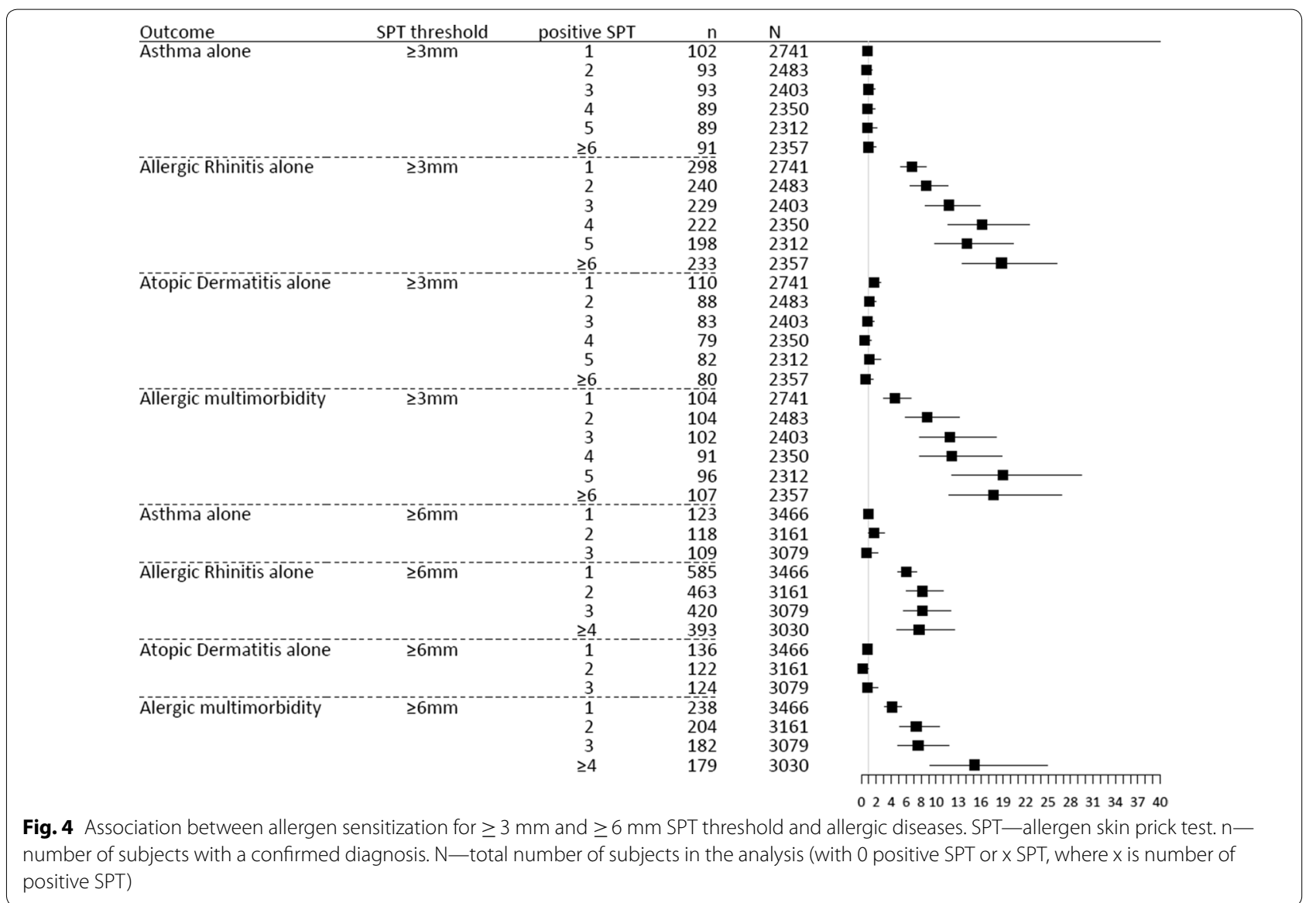

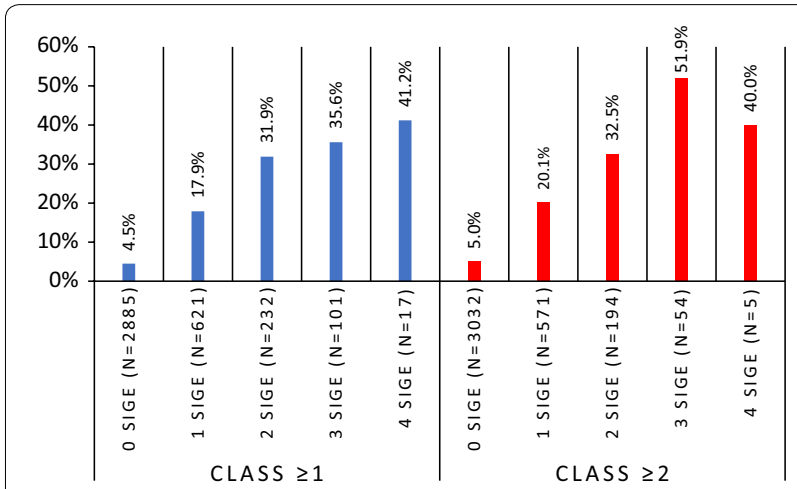

Fig. 5 Percentage of people with allergic multimorbidity by the number of positive allergen-specific lgE assays (4 allergens: $\mathrm{d} 1, \mathrm{e}$, m6, g6). X axis—slgE assay; Y axis_\% of multimorbidity among those with positive slgE for 0, 1, 2 and 3 allergens

\section{Multivariate analysis}

The logistic regression model explaining multimorbidity was based on data on age categories, gender, cooccurrence of other types of allergies (except A, AR and $\mathrm{AD}$ ) and SPT results. The -2 Log-likelihood value was 1933.896 (Cox \& Snell $R^{2}=0.111$, Nagelkerke's $\left.R^{2}=0.241\right)$. Among the variables analysed, there was a statistically significant relationship between multimorbidity and age categories (children and adolescents had a higher risk of multimorbidity than adults), food allergy and urticaria (higer risk), and positive SPTs for cat (high risk) and mites (high risk). The strongest impact on the risk of multimorbidity in the regression model was exerted by polysensitization for the threshold level of $\geq 3 \mathrm{~mm}$. However, a clear impact was also seen in the case of monosensitisation (Table 2). 


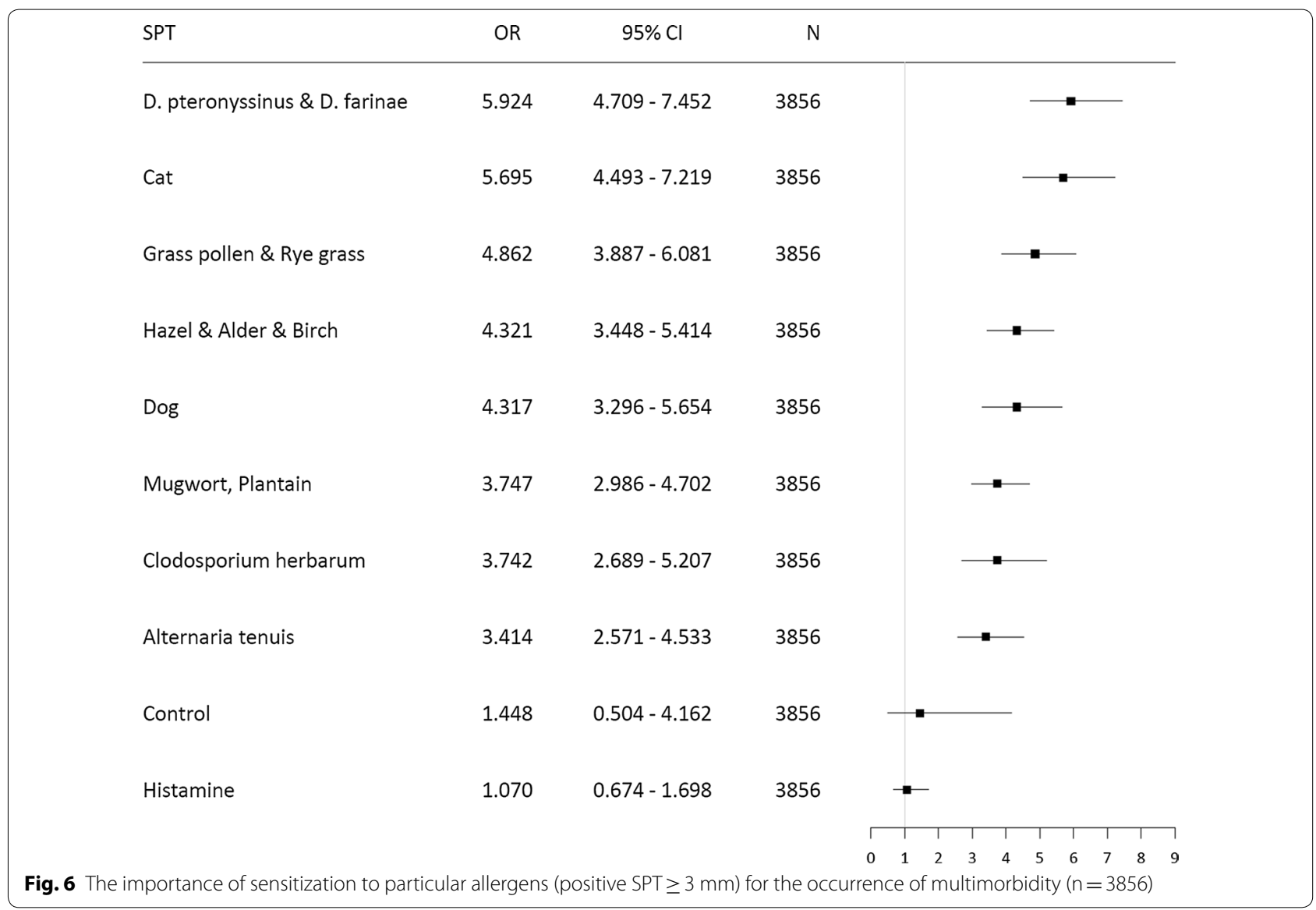

Table 2 The influence of different parameters on multimorbidity (logistic regression)

\begin{tabular}{|c|c|c|c|}
\hline \multirow[t]{2}{*}{ Name of variable } & \multirow[t]{2}{*}{ OR } & \multicolumn{2}{|l|}{$95 \% \mathrm{Cl}$} \\
\hline & & Lower & Upper \\
\hline Age: $6-7$ years & 2.001 & 1.467 & 2.729 \\
\hline Age: $13-14$ years & 1.426 & 1.071 & 1.899 \\
\hline Sex: Male & 1.033 & 0.812 & 1.314 \\
\hline Food allergy & 2.397 & 1.726 & 3.328 \\
\hline Drug allergy & 1.025 & 0.581 & 1.809 \\
\hline Insect venom allergy & 1.464 & 0.774 & 2.770 \\
\hline Urtricaria & 1.645 & 1.118 & 2.419 \\
\hline $\operatorname{Dog}(\mathrm{SPT})$ & 1.149 & 0.832 & 1.585 \\
\hline Cat (SPT) & 1.679 & 1.253 & 2.251 \\
\hline Cladosporium herbarum (SPT) & 1.109 & 0.748 & 1.643 \\
\hline Alternaria tenuis (SPT) & 1.010 & 0.726 & 1.406 \\
\hline Hazel \& Alder \& Birch (SPT) & 1.058 & 0.785 & 1.426 \\
\hline D. pteronyssinus \& D. farinae (SPT) & 1.695 & 1.247 & 2.305 \\
\hline Grass pollen \& Rye grass (SPT) & 1.166 & 0.855 & 1.591 \\
\hline Mugwort, Plantain (SPT) & 0.991 & 0.739 & 1.329 \\
\hline Monosensitisation (SPT) & 3.512 & 2.289 & 5.388 \\
\hline Polysensitisation (SPT) & 5.655 & 3.381 & 9.459 \\
\hline Constant & 0.488 & & \\
\hline
\end{tabular}

Reference line: female, age $20-44$, all SPTs negative

\section{Discussion}

Allergy of chronic origin, especially in young children, manifests symptoms (of varying degrees of severity) from various organs/systems and is multifactorial in nature [27]. Multicentre cohort studies conducted in the population of young children showed strong coexistence between the response to more than 2 allergens and multiple morbidities, which concerned the co-occurrence of bronchial asthma, allergic rhinitis, eczema and allergic conjunctivitis [27, 28]. An association between multiple morbidities and multiple allergies was also observed in adults [15]. Our study involved both children and adults. In both these groups, an association between multiple morbidities and multiple allergies was found.

Multimorbidity is strongly associated with AR or A and, to a lesser extent, with AD. This paper offers novel findings and shows also association with food allergy and urticaria. Moreover, the paper brings other novel findings. Asthma or AD as single diseases are not associated with sensitization. Allergic rhinitis is associated with polysensitization but more so for $\mathrm{SPT} \geq 3 \mathrm{~mm}$. Multimorbidity is associated with polysensitization for SPT $\geq 3$ and $\geq 6 \mathrm{~mm}$. Cat is the allergen most strongly associated with multimorbidity. 


\section{Strengths and limitations}

The study used canonical epidemiologic methods with validated methods for the diagnosis of allergic diseases. Moreover, the diagnosis was made by trained physicians and incorrect diagnoses are unlikely.

Diagnosis of polysensitization in the study was based on a SPT (8 groups of allergens) or sIgE assay (4 antibodies).

Only three allergic diseases (A, AR, AD) were included in the multimorbidity analysis because (i) this is the classical approach to allergic multimorbidity and (ii) we wanted to assess the impact of other allergic diseases in multimorbidity. Consideration of other allergic diseases in multimorbidity (e.g. food allergy) might have led to different conclusions.

Among the subjects with diagnosed AR, 14.5\% (15.9\% for AR alone) had a negative SPT. These diagnoses were based on clinical history. These cases require further analysis.

Due to the multicentre character the study was representative for individual age groups in each of the analysed 9 centres, however, it was not representative at the country level.

\section{Interpretation of the findings}

A, AR and AD were clearly associated with allergic multimorbidity. Also food allergy and urticaria increased the risk of multimorbidity. The role of venom allergy is more complex since the multivariable analysis showed no association, but according to a two-variable analysis it increased the risk. There was no association with drug allergy.

It is important to characterise multimorbidity across the life cycle. Although monosensitization and single allergic diseases are more common in infants, multimorbidity and polysensitization are found in preschool children [29-34]. The present study shows that multimorbidity is more common in children but also exists in adults, confirming the study of Siroux et al. [15].

Therefore it is essential to attempt to determine factors influencing the development of allergic multimorbidity. Ciprandi indicated that polysensitization co-occurs with multimorbidity [34]. Usually, polysensitization is more common than monosensitization, which was also demonstrated in this study (Table 1). Multimorbidity is also usually associated with a more severe course of AR and A. If it co-occurs with $\mathrm{AD}$ in adults, its clinical picture is usually characterised by severe, chronic dermatitis and respiratory tract inflammation $[34,35]$.

In the present study, the risk of multimorbidity was significantly associated with polysensitization. Multimorbidity was rare in case of negative SPTs, more frequent in subjects with one positive SPT reaction and very frequent in those with 2 or more positive SPT reactions to common inhalant allergens. Both SPT and slgE data were analysed, since according to epidemiologic studies, they show considerable overlap, but they do not have the same value for the interpretation of the allergic risk [36]. In cases of strongly positive reactions in SPT the significant association is present for at least 4 allergens.

Interestingly, $\mathrm{A}$ or $\mathrm{AD}$ alone were not associated with polysensitization (Fig. 4 and Additional file 1: Table 4). Polysensitization was associated with multimorbidity for SPT size of $\geq 3$ or $\geq 6 \mathrm{~mm}$. For AR, association with polysensitization was only shown for $\mathrm{SPT} \geq 3 \mathrm{~mm}$. These data suggest that $\mathrm{A}$ or $\mathrm{AD}$ alone, are different phenotypes in comparison to multimorbid A or AD. The data related to the size of the SPT reaction are compelling and may suggest differences depending on the size of the SPT. More studies are needed to understand this finding.

Moreover, attention should be paid to the significance of A in cases of multimorbidity. A was not the most common disease entity occurring in cases of multimorbidity, but if it was diagnosed in a patient, the probability of multimorbidity was significantly higher. The present results refer both to the group of patients diagnosed with allergic diseases and to the group of individuals without diagnosed allergies. This kind of analysis was conducted because both positive SPT reactions and the presence of slgE in serum might occur in people without allergy or, conversely, allergic symptoms might be present in patients with negative SPTs as suggested by topical allergy, e.g. Rh without antibodies in blood serum [37, 38]. This observation confirms the conclusion of Bousquet et al.: "Rhinitis is usually associated with mono- or polysensitization, whereas A is more often associated with polysensitization and multimorbidities" [30].

The present study was not focused on asymptomatic patients. However, it has to be noted that this phenomenon should be taken into account in further analysis and might be relevant in determining the significance of specific disease entities in the development of multimorbidity and polysensitization.

Not only polysensitization plays an important role in multimorbidity; the species of allergens are also important. Sensitization to cat or house dust mites (HDM) was more strongly associated with multimorbidity than to pollens or moulds. Although cat and HDM are perennial allergens, hazel and grasses are not. However, in the Polish climate these two allergens (together with birch and alder, which exhibit strong cross-reactivity with hazel) have a long pollen season from the end of January to April. These data suggest that long-acting allergens may play an important role in multimorbidity because of prolonged time of exposure. 
Age plays some role in multimorbidity. The prevalence of multimorbidity was more common in children and adolescents than in subjects over 20 years of age.

\section{Generalisability}

This study and analysis prove that multimorbidity of allergic diseases is a different phenotype compared to A alone and $\mathrm{AD}$ alone. Asthma plays a crucial role in multimorbidity but only with coexisting rhinitis, polysensitization and perennial exposure to allergens.

\section{Conclusions}

The general conclusion of this study is that long-term exposure to allergens (e.g. mites and cat) and polysensitization are the strongest risk factors for the development of multimorbidity in allergy patients. A alone appears to be a different phenotype than $\mathrm{A}$ in multimorbidity, especially when coexisting with AR.

\section{Additional file}

Additional file 1. Results: data analysis—supplement.

\begin{abstract}
Abbreviations
A: asthma; AD: atopic dermatitis; AR: allergic rhinitis; d1: slgE: Dermatophagoides pteronyssinus; Der p: Dermatophagoides pteronyssinus; Der f: Dermatoipha goides farinae; e1: slgE: cat; EAACl: European Academy of Allergy and Clinical Immunology; ECAP: Epidemiology of Allergic Diseases in Poland; ECRHS: European Community Respiratory Health Survey; g6: slgE: Phleum pratense; ISAAC: International Study of Asthma and Allergy in Childhood; m6: slgE: Alternaria alternata; OR: odds ratio; Rh: rhinitis; HDM: house dust mites; slgE: specific immunoglobulin E; SPT: skin prick test.
\end{abstract}

\section{Authors' contributions}

FR: methodology conceptualization, statistical data analysis, results description. JB: general concept, writing the discussion and conclusion section. AN: analysis of slgE data. EK-F: literature review, writing the introduction section. AT: methodology description. BP: cooperation with other authors, editing of the article. PS-K: statistical data analysis, preparation of figures and tables. AZB: revising article critically for important intellectual content, final approval of the version to be published, corresponding author. AW: drafting the article or revising it critically for important intellectual content. AL, OW, KS, AS, WZ: analysis and interpretation of data. WZ: statistical consultations, verification of results. AS: drafting the article, analysis and interpretation of data. AG: desk research, assistance in writing introduction section. BS: supervision, writing the discussion and conclusion section. All authors read and approved the final manuscript.

\footnotetext{
Author details

${ }^{1}$ Department of Prevention of Environmental Hazards and Allergology, Medical University of Warsaw, Warsaw, Poland. ${ }^{2}$ MACVIA-France and Fondation FMC VI-LR, Montpellier, France. ${ }^{3}$ Ageing and Chronic Diseases, Epidemiological and Public Health Approaches, U1168, INSERM, VIMA, Paris, France. ${ }^{4}$ UMR-S 1168, Université Versailles St-Quentin-en-Yvelines (UVSQ), Paris, France. ${ }^{5}$ Euforea, Brussels, Belgium. ${ }^{6}$ Charité, Berlin, Germany. ${ }^{7}$ Allergy and Clinical Immunology Department, Central Hospital Medical University of Warsaw, Warsaw, Poland. ${ }^{8}$ Public Health Department, Medical University of Warsaw, Warsaw, Poland. ${ }^{9}$ Department of Econometrics and Statistics, Warsaw University of Life Sciences, Warsaw, Poland.
}

\section{Competing interests}

Filip Raciborski, Jean Bousqet, Andrzej Namysłowski, Edyta Krzych-Fałta, Aneta Tomaszewska, Barbara Piekarska, Piotr Samel-Kowalik, Artur Z. Białoszewski, Artur Walkiewicz, Agnieszka Lipiec, Oksana Wojas, Krzysztof Samoliński, Anna Szylling, Wojciech Zieliński, Adam Sybilski, Aleksandra Grąbczewska, Bolesław Samoliński have nothing to disclose.

\section{Ethical approval}

The study was approved by the institutional Bioethics Committee (Warsaw Medical University Bioethics Committee - KB/206/2005). All participants or caregivers approved the study procedures and written informed consent was obtained from each subject.

\section{Funding}

The project Epidemiology of Allergic Diseases in Poland (ECAP) is an allergic epidemiological study conducted in Poland. It consists of two phases: an initial fieldwork phase (research grant from Ministry of Health and Ministry of Science and Higher Education (Poland) 03788/C.P05-6/2005) and a second laboratory-based study (research grant from the National Science Centre (Poland), 2011/01/B/NZ7/05289).

\section{Publisher's Note}

Springer Nature remains neutral with regard to jurisdictional claims in published maps and institutional affiliations.

Received: 19 September 2018 Accepted: 4 January 2019

Published online: 11 February 2019

\section{References}

1. Ponińska J, Samoliński B, Tomaszewska A, Raciborski F, Samel-Kowalik P, Walkiewicz A, et al. Filaggrin gene defects are independent risk factors for atopic asthma in a Polish population: a study in ECAP cohort. PLOS ONE. 2011;6(2):e16933. https://doi.org/10.1371/journ al.pone.0016933.

2. Ponińska JK, Samoliński B, Tomaszewska A, Raciborski F, Samel-Kowalik P, Walkiewicz A, et al. Haplotype dependent association of rs7927894 (11q13.5) with atopic dermatitis and chronic allergic rhinitis: a study in ECAP cohort. PLOS ONE. 2017;12(9):e0183922. https://doi.org/10.1371/ journal.pone.0183922.

3. Ballardini N, Kull I, Soderhall C, Lilja G, Wickman M, Wahlgren CF. Eczema severity in preadolescent children and its relation to sex, filaggrin mutations, asthma, rhinitis, aggravating factors and topical treatment: a report from the BAMSE birth cohort. Br J Dermatol. 2013;168:588-94.

4. Ferreira MA, Matheson MC, Tang CS, Granell R, Ang W, Hui J, et al. Genome-wide association analysis identifies 11 risk variants associated with the asthma with hay fever phenotype. J Allergy Clin Immunol. 2014;133:1564-71.

5. Bousquet J, Anto JM, Wickman M, Keil T, Valenta R, Haahtela T, et al. Are allergic multimorbidities and IgE polysensitization associated with the persistence or re-occurrence of foetal type 2 signalling? The MeDALL hypothesis. Allergy. 2015;70(9):1062-78.

6. Asher MI, Montefort S, Björkstén B, Lai CK, Strachan DP, Weiland SK, et al. Worldwide time trends in the prevalence of symptoms of asthma, allergic rhinoconjunctivitis, and AD in childhood: ISAAC Phases One and Three repeat multicountry cross-sectional surveys. Lancet. 2006;368:9537.

7. Bousquet J, Khaltaev N. Global surveillance, prevention and control of chronic respiratory diseases. A comprehensive approach. Global alliance against chronic respiratory diseases. WHO: World Health Organization. ISBN 978924156346 8. 2007. p. 148.

8. Shaaban R, Zureik M, Soussan D, Neukirch C, Heinrich J, Sunyer J, et al. Rhinitis and onset of asthma: a longitudinal population-based study. Lancet. 2008;372(9643):1049-57.

9. Cingi C, Gevaert P, Mösges R, Rondon C, HoxV, Rudenko M, et al. Multimorbidities of allergic rhinitis in adults: European Academy of Allergy and Clinical Immunology Task Force Report. Clin Transl Allergy. 2017;1(7):17. https://doi.org/10.1186/s13601-017-0153-z. 
10. Bousquet J, Van Cauwenberge P, Khaltaev N, Aria Workshop Group; World Health Organization. Allergic rhinitis and its impact on asthma. J Allergy Clin Immunol. 2001;108(5 Suppl):S147-334.

11. Leynaert B, Neukrich C, Kony S, Guénégou A, Bousquet J, Aubier M, et al. Association between asthma and rhinitis according to atopic sensitization in a population-based study. J Allergy Clin Immunol. 2004;1:86-93.

12. Samoliński B, Raciborski F, Tomaszewska A, Walkiewicz A, Samel-Kowalik P, Lusawa A, et al. Epidemiology of allergic diseases in Poland-ECAP study [original title: Wyniki badań programu Epidemiologia Chorób Alergicznych w Polsce (ECAP)]. Kształcenie podyplomowe. 2011;3(1):12-21.

13. Vandenplas O, Dramaix M, Joos G, Louis R, Michils A, Verleden G, et al. The impact of concomitant rhinitis on asthma-related quality of life and asthma control. Allergy. 2010;65(10):1290-7.

14. Galobardes B, McCarron P, Jeffreys M, Davey Smith G. Association between early life history of respiratory disease and morbidity and mortality in adulthood. Thorax. 2008;63(5):423-9.

15. Siroux V, Ballardini N, Soler M, Lupinek C, Boudier A, Pin I, et al. The asthma-rhinitis multimorbidity is associated with lgE polysensitization in adolescents and adults. Allergy. 2018;73(7):1447-58. https://doi. org/10.1111/all.13410

16. Iribarren C, Tolstykh I, Miller MK, Sobel E, Eisner MD. Adult asthma and risk of coronary heart disease, cerebrovascular disease, and heart failure: a prospective study of 2 matched cohorts. Am J Epidemiol. 2012;176(11):1014-24

17. Samolinski B, Fronczak A, Kuna P, Akdis CA, Anto JM, Bialoszewski AZ, et al. Prevention and control of childhood asthma and allergy in the EU from the public health point of view: Polish Presidency of the European Union. Allergy. 2012;67(6):726-31.

18. Samolinski B, Fronczak A, Wlodarczyk A, Bousquet J. Council of the European Union conclusions on chronic respiratory diseases in children. Lancet. 2012;379(9822):e45-6.

19. Hellings PW, Borrelli D, Pietikainen S, Agache I, Akdis C, Bachert C, et al. European Summit on the Prevention and Self-Management of Chronic Respiratory Diseases: report of the European Union Parliament Summit (29 March 2017). Clin Transl Allergy. 2017;27(7):49. https://doi. org/10.1186/s13601-017-0186-3.

20. www.strobe-statement.org. Accessed 5 Aug 2018.

21. Krzych-Fałta E, Furmańczyk K, Piekarska B, Tomaszewska A, Sybilski A, Samoliński BK. Allergies in urban versus countryside settings in Poland as part of the Epidemiology of the Allergic Diseases in Poland (ECAP) study_challenge the early differential diagnosis. Adv Dermatol Allergol. 2016:33(5):359-68. https://doi.org/10.5114/pdia.2016.61338.

22. www.ecap.pl. Accessed 5 June 2008.

23. Gíslason D, Bjœrnsdóttir US, Blœndal T, Gíslason T. European Community Respiratory Health Survey: the main results so far with special reference to Iceland. Laeknabladid. 2002;88(12):891-7.

24. Asher MI, Keil U, Anderson HR, Beasley R, Crane J, Martinez F, et al. International Study of Asthma and Allergies in Childhood (ISAAC): rationale and methods. Eur Respir J. 1995:8(3):483-91.
25. Hanifin JM, Rajka G. Diagnostic features of atopic dermatitis. Acta Derm Venereol Suppl (Stockh). 1980;92:44-7.

26. Bousquet J, Heinzerling L, Bachert C, Papadopoulos NG, Bousquet PJ, Burney PG, et al. Global Allergy and Asthma European Network; Allergic Rhinitis and its Impact on Asthma. Practical guide to skin prick tests in allergy to aeroallergens. Allergy. 2012;67(1):18-24. https://doi.org/10.111 1/j.1398-9995.2011.02728.X

27. Ha EK, Baek JH, Lee SY, Park YM, Kim WK, Sheen YH, et al. Association of polysensitization, allergic multimorbidity, and allergy severity: a cross-sectional study of school children. Int Arch Allergy Immunol. 2016;171(3-4):251-60.

28. Gabet S, Just J, Couderc R, Bousquet J, Seta N, Momas I. Early polysensitization is associated with allergic multimorbidity in PARIS birth cohort infants. Pediatr Allergy Immunol. 2016;27(8):831-83.

29. Fasce L, Tosca MA, Baroffio M, Olcese R, Ciprandi G. Atopy in wheezing infants always starts with monosensitization. Allergy Asthma Proc. 2007;28:449-53.

30. Bousquet J, Anto JM, Wickman M. Are allergic multimorbidities and lgE polysensitization associated with the persistence or re-occurrence of foetal type 2 signalling? The MeDALL hypothesis. Allergy. 2015;70:1062-78.

31. Hahn EL, Bacharier LB. The atopic march: the pattern of allergic disease development in childhood. Immunol Allergy Clin North Am. 2005;25:231-46.

32. Spergel JM. Epidemiology of atopic dermatitis and atopic march in children. Immunol Allergy Clin North Am. 2010;30:269-80.

33. Tronnes H, Wilcox AJ, Lie RT, Markestad T, Moster D. The association of preterm birth with severe asthma and atopic dermatitis: a national cohort study. Pediatr Allergy Immunol. 2013;24:782-7.

34. Ballardini N, Kull I, Soderhall C, Lilja G, Wickman M, Wahlgren CF. Eczema severity in preadolescent children and its relation to sex, filaggrin mutations, asthma, rhinitis, aggravating factors and topical treatment: a report from the BAMSE birth cohort. Br J Dermatol. 2013;168:588-94.

35. Ciprandi G, Cirillo I. Monosensitization and polysensitization in allergic rhinitis. Eur J Intern Med. 2011;22:e75-9.

36. Schoos AM, Chawes BL, Folsgaard NV, Samandari N, Bonnelykke K, Bisgaard $\mathrm{H}$. Disagreement between skin prick test and specific IgE in young children. Allergy. 2015;70:41-8.

37. Campo P, Eguiluz-Gracia I, Bogas G, Salas M, Plaza Serón C, et al. Local allergic rhinitis: implications for management. Clin Exp Allergy. 2018;1:2. https://doi.org/10.1111/cea.13192.

38. Campo P, Salas M, Blanca-López N, Rondón C. Local allergic rhinitis. Immunol Allergy Clin North Am. 2016;36(2):321-32. https://doi. org/10.1016/j.iac.2015.12.008.

\footnotetext{
Ready to submit your research? Choose BMC and benefit from:

- fast, convenient online submission

- thorough peer review by experienced researchers in your field

- rapid publication on acceptance

- support for research data, including large and complex data types

- gold Open Access which fosters wider collaboration and increased citations

- maximum visibility for your research: over $100 \mathrm{M}$ website views per year
}

At BMC, research is always in progress.

Learn more biomedcentral.com/submissions 